distinct imprint during Heinrich events, exhibiting rapid changes during glacials and interglacials alike. The existing pollen data cover the last 5 interglacial periods and there are clear linkages between sea surface water conditions off Iberia and forest expansion/retraction on the Peninsula. Open issues that need to be addressed in the future are apparent phase differences between forest expansion/retraction at the NW and SW Iberian Margin and potential marine moisture source(s) for vegetation dynamics. Re- construction of hydrological conditions on land is making good progress, even though some time series are affected by stratigraphic hiati due to mountain glacier advances. For the Holocene, aridity events on land can clearly be correlated with WMDW variability off Menorca. Additional information on terrestrial environments and prevailing wind patterns may come from charcoal records in deep-sea cores like the study presented for site MD95-2042.
Papers resulting from the workshop will be published in a Geochemistry, Geophysics, Geosystems $\left(G^{3}\right)$ special theme.

\section{Acknowledgements}

This workshop was co-sponsored by IMAGES, PAGES and the Fundação para a Ciência e a Tecnologia (FCT), with additional support from the Empresa de Desenvolvimento Mineiro (EDM), the Foundation for Luso-American Development (FLAD), and the city hall of Peniche.

\title{
Salinity, climate change and salinization
}

\section{LIMPACS 2nd Workshop, 11-14 April 2007, Nanjing, China}

\section{ShiJie LI ${ }^{1}$, P. GeLL ${ }^{2}$, AND S. FRITZ ${ }^{3}$}

${ }^{1}$ Chinese Academy of Sciences; shijie@niglas.ac.cn; ${ }^{2}$ University of Adelaide, Australia; peter.gell@adelaide.edu.au; ${ }^{3}$ University of Nebraska, Lincoln, USA; sfritz2@uni.edu

Forty-five participants attended a workshop focused on climate change and human impact on lake systems and water resources in arid and semi-arid regions sponsored by PAGES, the Chinese Academy of Science (CAS), and the Chinese Natural Science Foundation. Scientific papers were presented primarily on research from China, Mongolia, and India but also included presentations on sites in Africa, Australia, and North and South America. Workshop discussion focused on integrating monitoring, modeling, and paleoenvironmental approaches to evaluate change and to coordinating research under this theme within the Asian region.

Talks on the first day dealt with observations and modeling of contemporary limnological variability and recent and projected climate change. Several lakes in Tibet have measurements of key limnological and climatic variables that span more than 30 years, and presentations highlighted efforts to understand the linkages between recent lake-level change and changes in atmospheric circulation in both glaciated and non-glaciated catchments. The second day focused on paleoclimatic records that spanned from a few hundred years to hundreds of thousands of years and have been used to reconstruct the history of the Asian monsoon systems. Many of the sites have paleoshorelines (Fig. 1) that can be used to link core and geomorphic records and generate quantitative models of volumetric changes in hydrology. A field trip on the final day included a visit to Taihu, one of the largest Chinese freshwater lakes, which serves as a source of drinking water for Shanghai. Ongoing research on eutrophication and metal pollution in the lake were highlighted in a visit to a field station on the

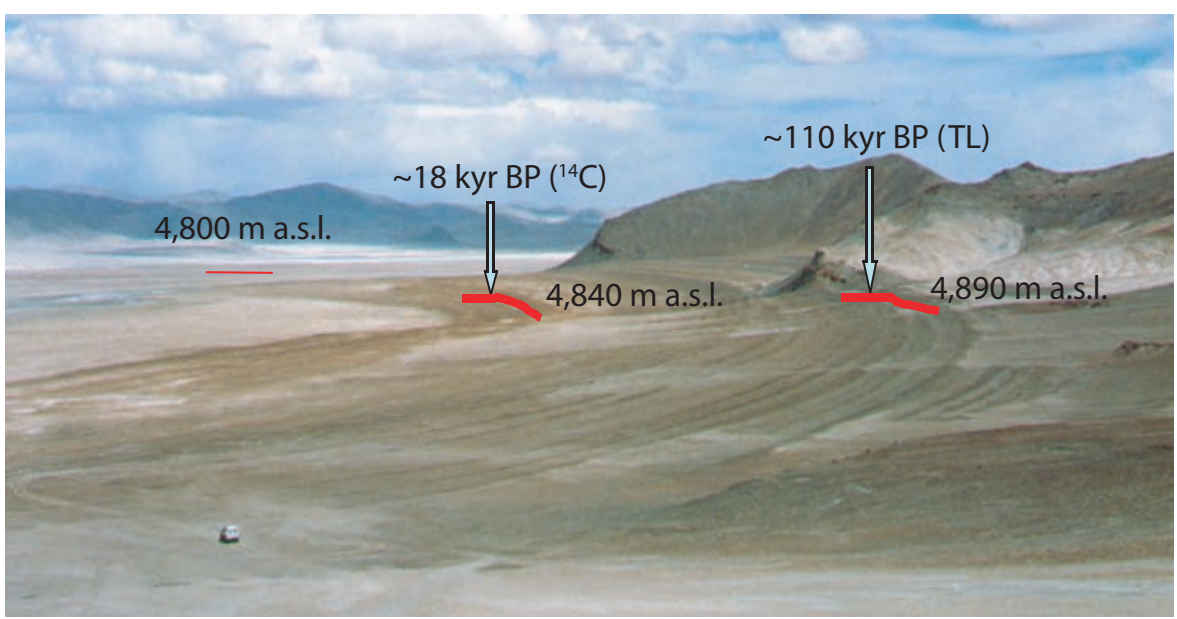

Figure 1: Lake shoreline in the Tianshuihai Basin, south slope of west Kunlun Mountains, NW Tibetan Plateau (Photo by Shijie Li).

lake run by the Nanjing Institute of Geography and Limnology, CAS, and management issues were raised in a meeting with the vice director of the Environmental Protection Bureau of one of the major cities in the lake's catchment.

Discussion sessions during the meeting covered a range of topics relating to the challenges of integrating contemporary and paleoclimatic studies and of reconstructing climate history from lakes. It was suggested that monitoring efforts should center on measuring simple variables that can be scaled to climatically relevant data, such as lake level measurements, to generate integrated basin precipitation. Others emphasized the advantages of integrating cores from both littoral and deep-water areas, which may reflect different types of climatically driven catchment and lake change. Much of the discussion considered issues related to what is known about the history of the Asian monsoon systems and the relevance of these data for the future. It was agreed that additional high-resolu- tion records are needed to complement the iconic speleothem records from Dongge and Hulu Caves, and that the potential for high temporal resolution in many Chinese and Mongolian lake systems has not been fully exploited. Participants also discussed the application of paleo data to policy decisions and to sustainable environmental management.

A key output of discussions was the generation of an informal research network across Asia to examine the influence of the eastern and southern (Indian) monsoon and westerlies on climate variability in the region. Three research foci centering on Mongolian, Tibetan and Indian lakes were proposed to advance research directed at distinguishing the influence of climate change and people on lake status and water resources in the present and future. It was proposed that the preliminary outcomes of the network be shared at the 3rd workshop proposed for Delhi, India in February-March 2009. 